Massey University, New Zealand

${ }^{2}$ Metlifecare, New Zealand

\section{AOTEAROA}

NEW ZEALAND SOCIAL WORK 29(4), 84-96.

CORRESPONDENCE TO: Polly Yeung

p.yeung@massey.ac.nz

\title{
What matters most to people in retirement villages and their transition to residential aged care
}

\author{
Polly Yeung ${ }^{1}$, Gretchen Good ${ }^{1}$, Kieran O'Donoghue', Sarah Spence ${ }^{2}$, Blanka Ros ${ }^{2}$
}

\begin{abstract}
INTRODUCTION: As older people age and become frail, their decline in independence and concomitant changing care needs may force them to move from retirement village to a residential aged care (RAC) facility. The purpose of this study was to identify factors that contribute to subjective wellbeing among older people living in retirement villages in Aotearoa New Zealand and to compare results with the data from the residents of the care home facilities co-located with the retirement villages.

METHOD: This study is mainly quantitative in nature to examine what factors contributed to subjective wellbeing among older people living in retirement villages. Descriptive and regression analyses were used with data collected in 2016 from residents of two retirement villages ( $N=163$ ) from one aged residential care provider in Aotearoa New Zealand and they were then compared with already-published data on RAC residents. In addition, four village residents participated in semi-structured interviews.
\end{abstract}

RESULTS: Results showed that retirement village residents reported being generally satisfied with their living environment and their overall wellbeing is positively influenced by their social and psychological milieu.

CONCLUSIONS: This research provides insights on what matters most to retirement village residents' subjective wellbeing, which includes a dignified environment enhancing positive mental health, relationship building and reducing loneliness and isolation. Results were also compared with feedback from care home residents co-located in the same estate to provide an indicative picture for comparison against other studies to inform and expand choices for older people to consider when relocating in late-life.

KEYWORDS: subjective wellbeing; retirement villages; housing options; quality of living; ageing; quality of life

\section{Introduction}

Population ageing is a worldwide phenomenon. In Aotearoa New Zealand, the ageing population (65+) is projected to grow to between 1.28 and 1.37 million by 2041 , representing an increase of 715,000 or $166 \%$ since 1996 (Statistics New Zealand, 2014). The growth in this age group not only leads to a corresponding demand for appropriate housing, but also a demand for security, socialisation and health-related support services. This also means the need for aged residential care will increase substantially. The Health of Older People Strategy (Ministry of Health, 2002) emphasised the importance of planning for the care and support of older people due to growing service 
needs. To support the independence and activity of older people, suitable housing alternatives are required. The last 30 years have seen changes on the ageing landscape in Aotearoa New Zealand, resulting in the emergence of retirement villages. The term retirement village, in both Australia and Aotearoa New Zealand usually refers to a "continuing care retirement community" (CCRC) in North America and "sheltered housing" in the United Kingdom (Howe, Jones, \& Tilse, 2013). This type of longterm care community provides varying levels of care depending on the needs of the older people, including independent living apartments, assisted living, and residential aged care (RAC)/nursing homes (Klinedinst \& Resnick, 2014). Although terms utilised to describe retirement villages vary around the world, a retirement village can generally be depicted as an olderperson-based community that provides a variety of accommodations, services and facilities (U'Ren, 2013). According to the New Zealand Law Commission (1999), a retirement village is a purpose-built complex of residential units with access to a range of ancillary facilities planned specifically for the comfort and convenience of the residents. Similar to CCRC, retirement villages in Australia and Aotearoa New Zealand often permit residents to remain in one facility to provide continuing care, while moving between levels of care as their needs change: independent living, assisted living, and RAC (Hu, Xia, Skitmore, Buys, \& Zuo, 2017). The latest figures from the New Zealand Retirement Villages Association (NZRVA) indicated that almost 33,000 people throughout Aotearoa New Zealand are living in more than 300 villages registered under the Retirement Village Act 2003 (Webster, 2017).

Declining physical health and mobility are the most commonly reported reasons for late-life relocation. Retirement villages, particularly those co-located with RAC facility, may represent the "last stop" in older peoples' lives (Shippee, 2012); with a continued emphasis on independent living in later life and ageing in place rather than the more traditional forms of aged care environments (Chandler \& Robinson, 2014). The aim is also to assist older adults to remain in their own homes, which is consistent with many older adults' wishes (Black \& Dobbs, 2014). To achieve this, retirement villages provide support services (e.g., transportation, companionship, health care advocacy) and often have recreational facilities to enable residents to age-in-place for longer and to maintain autonomy and control over their lives (Emlet \& Moceri, 2012; Gardner, Browning, \& Kendig, 2005; Graham \& Tuffin, 2004).

Negative perceptions of retirement communities have been identified in the literature, for example, as a step in the progression to an aged care facility where one might face the loss of privacy and independence (Crisp, Windsor, Anstey, \& Butterworth, 2013; McLaughlin \& Mills, 2008). There is also a perception that retirement villages isolate and segregate older people from mainstream society (Bohle, Rawlings-Way, Finn, Ang, \& Kennedy, 2014). Positive perceptions have also been reported. A number of Australian studies have stated the positive impact of living in retirement villages on maintaining autonomy (Montague, 1982); health-related quality of life and social connectedness (Stimson, McCrea, \& Star, 2002); and positive satisfaction with living situation (Ferris \& Bramston, 1994; Manicaros \& Stimson, 1999). Recent research in the USA has also indicated that living in retirement villages can reduce loneliness and isolation, improve wellbeing and allow older people to continue to age in place with confidence (Graham, Scharlach, \& Wolf, 2014).

Research from overseas has reported that the majority of older people living in retirement villages have a higher quality of life when compared with older adults living in RAC, hostels and family homes (Ferris \& Bramston, 1994; Gardner et al., 2005; Kennedy \& Coates, 2008). Surveys conducted by the NZRVA in 2003 and 2006 of residents living in villages 
both reported residents' overall satisfaction with their living place as extremely high (89\% satisfied/very satisfied and 99\% satisfied/ very satisfied respectively) (Webster, 2015). Graham and Tuffin's (2004) study where they interviewed 12 village residents living in Aotearoa New Zealand reported that both companionship and privacy were important contributors in a retirement village for a worry-free environment. Grant (2007) interviewed 121 village residents in Aotearoa New Zealand and they reported their village living experiences were positive, secure and supportive, which helped develop a sense of belonging. Based on the existing research, retirement villages represent a practical model for living that can enhance the wellbeing of community-dwelling older people, and help them to maintain their independence, enhance their social connection and remain living in their own homes while surrounded by care services, if needed.

As older people age and become frail, their decline in independence and concomitant changing care needs may force them to move from retirement villages to a RAC facility. Research has indicated that, while transition to retirement living is a turning point in the life course (Moen, Erickson, \& DempsterMcCain, 2000), transition to another level of care such as RACs can be more stressful as decisions to enter institutional care are often unplanned due to an acute medical crisis. While older people tend to voluntarily move to retirement villages to protect their autonomy as they age (Heisler, Evans, \& Moen, 2004), the transition into RAC is considered to be the last resort and research has reported that older people often experience a sense of anger and helplessness and their carers or family members may feel guilty and stressed after the transition (Cheek, Ballantyne, Byers, \& Quan, 2006). Relocation into and between facilities is very challenging to older people's quality of life and wellbeing and this can affect one's privacy, dignity and independence (Brownie \& Horstmanshof, 2012; Yeung et al., 2016). The advantage of some retirement villages being co-located with RAC facilities can provide services and support to residents of the colocated retirement villages. However, earlier research by Fisher (1987), and Jenkin, Pienta, and Horgas (2002) have indicated that the benefits of such continuum of care are not equally distributed and that transitions in a multilevel care facility were more difficult than many residents anticipated. One Aotearoa New Zealand study reported an implementation of a nurse-led clinic for village residents to receive nursing care in the RAC facility has proved beneficial for village residents to gain more confidence in the nursing staff and reduce some misconceptions about life as a RAC resident (Meek, 2011).

Existing literature has provided some comprehensive scope for understanding relocations in later life and the decision to move to retirement villages and its adjustment process. Nevertheless, there is limited research on comparing factors contributing to quality of life and wellbeing between retirement village residents and RAC residents within a single continuum of care in order for older people and/or their family members to make informed decisions about what is a good place to age if/when older people's health and mobility starts to decline - particularly if they want to stay in the same complex and community. The present study sought to explore the issues and factors that contribute to subjective wellbeing among older people living in two retirement villages in Aotearoa New Zealand and subsequently to compare the results with the published data from the RAC residents co-located with the same two retirement villages (Yeung et al., 2016; Yeung \& Rodgers, 2017). Relocations that involve major changes in lifestyle can be very stressful for older people. Knowing what matters most to older people living in retirement villages can enable service provision to be developed to assist older people to age-in-place in a retirement village. When necessary, it can also enhance the predictability and expectations about impending relocation to a RAC facility that can lead to a more successful transition 
and reduce adverse outcomes including reduced residential satisfaction and reduced psychosocial wellbeing.

\section{Methods \\ Design and Setting}

This study setting involved a large provider of residential care in NZ. Established in 1984, the aged care services provided by this organisation offer three different levels of care, similar to the concept of CCRC (i.e., independent living/retirement village, assisted living and RAC options). In 2015, this care provider announced its move to a resident-centred care practice that focuses upon empowering residents, staff, families and other stakeholders to provide a better life for residents. They implemented a pilot project to survey two established estates which comprised residents in RAC facilities where residents have access to 24-hour care and support in an environment with a nurse manager and a team of registered nurses and trained caregivers; and in retirement villages (independent living in villas, apartments and cottages where assistance with daily chores can be purchased and also staffed by professional nursing staff to assist with health-related issues) exploring their quality of life and satisfaction with care they received. The design of the project also included qualitative data by interviewing some of the residents from both retirement villages and RAC facilities. The current article focuses on reporting the data collected from the retirement villages in order to compare these with the published results from RAC residents (Yeung et al., 2016; Yeung \& Rodgers, 2017). Although the bulk of the data reported in this article is of a quantitative nature, the small cohort and limited scope of qualitative data was able to help illustrate and explain some of the findings that emerged from the quantitative data. Surveys were developed by the organisation and data were collected for the organisation by an independent research agency. The first three authors' main role was to analyse the data. Low-risk approval was given by the Massey University Research Human Ethics Committee on 24 June, 2015 to conduct the analysis.

\section{Participants}

Two of the organisation's retirement villages in Auckland were chosen to participate in this research. Each retirement village is situated in a large complex where there is plenty of land with beautiful gardens, staff available $24 / 7$ for added security and it is also located within walking distance of local shops, community clubs and medical facilities. Out of the 255 village resident who were sent surveys, 163 completed and returned them, giving a response rate of $64 \%$. From the 163, four retirement village residents, two males and two females aged between 70 and 76 years of age, agreed to participate in face-to-face interviews. On average, they had been living in the retirement villages for more than two years.

\section{Measures}

Some of the measurements used and discussed later came from a previous study undertaken by Yeung and Rodgers (2017) on older residents living in RAC facilities. As the cohort concerned was residents from retirement villages, some wording in the scales was modified, for example, "easy to make friends at the care home" was changed to "easy to make friends at the village." The rationale for using the same instruments and methodologies from previous research conducted by Yeung et al. (2016) with retirement village residents was to allow for the possibility of making comparisons of the data between the two studies. To ensure the rigor of each measurement, where possible, Cronbach's alpha was used, followed by Confirmatory Factor Analysis (CFA), using the fit indices of the Goodness of Fit Index (GFI) value (>0.90) (Joreskog \& Sorbom, 1989), the Normed Fit Index (NFI) value $(>0.90)$ and Comparative Fit Index (CFI) value $(>0.90)$ to test construct validity (Hu \& Bentler, 1999). 
To measure what conditions contribute to village residents' quality of life, five domains of quality of life: Comfort, Privacy, Dignity, Meaningful Activities and Relationship, were used based on the work of Kane et al. (2003) which aligns with resident-centred practices (White, Newton-Curtis, \& Lyons, 2008). These scales comprised one to five items and used a 5-point Likert scale ranging from $1=$ never to $5=$ always. Higher scores indicate better quality of life.

Four items were chosen to represent the construct of Positive Mental Health (PMH) as $\mathrm{PMH}$ was considered essential to residents living in congregated retirement housing (Sheikh \& Yesavage, 1986). Each item uses a 5-point Likert scale ranging from $1=$ strongly disagree to $5=$ strongly agree. Higher scores mean more positive self-perceived mental health.

The construct of Loneliness and Isolation (L\&I) was developed by adopting three items on loneliness, helplessness and boredom from the Eden Alternatives Warmth Surveys Residents (EWR-R) (Yeung et al., 2016). The EWR-R survey emphasised a philosophy of person-centred care, which focused on reducing loneliness, helplessness and boredom faced by residents living in a residential care complex. Each item was measured by a 5-point Likert scale ranging from 1 = strongly disagree to $5=$ strongly agree. The negatively keyed items were reversescored before computing individuals' total scores. Higher scores indicate feeling less lonely and isolated.

The construct of subjective wellbeing (SWB) was formed by using three single items to assess each village resident's: (a) living situation (How satisfied are you with the conditions of your current living place?); (b) satisfaction with life (All things considered, how satisfied are you with your life as a whole these days?) and (c) quality of life (How would you rate your quality of life?), using a 5-point Likert scale ranging from $1=$ strongly dissatisfied to $5=$ strongly satisfied. This construct has been used in research to measure older people's subjective wellbeing
(La Grow, Yeung, Towers, Alpass, \& Stephens, 2011; Yeung \& Breheny, 2016).

The interview was designed around two particular questions on: (1) the experiences of residents living in retirement villages; and (2) how the implementation of a residentcentred approach by the organisation which provides continuing care has influenced their views on relocating into RAC facilities/ care home if needed. All interviews were recorded and transcribed into text form by the project officer at the organisation. After the transcription, the responses from the four village residents were pooled and analysed by the first three authors to complement and illustrate the quantitative results.

Table 1 reports means, standard deviations, Cronbach's alpha and CFA of the items which constitute each of the variables used in this study, along with comparison to care home residents from previous research (Yeung et al., 2016; Yeung \& Rodgers, 2017). All negatively keyed items in any one of the scales were reverse-scored before computing individual mean scores.

\section{Data analysis}

With an alpha level of 0.05 , the data in the study were analysed using the IBM SPSS 23 (IBM SPSS, Chicago, IL, USA). Simple descriptive statistics of mean and standard deviation (SD) were used to describe respondents' responses on the various measures used. The data were screened to check the minimum and maximum values and distribution for all scales. SPSS preliminary frequency output was analysed for missing values. Frequency analysis for each item indicated that responses for each item/domain had minimum and maximum values within the range. The percentage of missing values was under $5 \%$ and random in nature. Therefore, the missing data were replaced with regression imputation as recommended by Tabachnick and Fidell (2013). A standard multiple regression was run with SWB serving as the dependent variable. Correlations were run to check 
Table 1. Comparison of Variables Between Village Residents and Care Home Residents

\begin{tabular}{|c|c|c|c|c|c|}
\hline Domain & Abbreviated Items* & $\begin{array}{l}\text { Current Study } \\
\qquad(N=163) \\
\text { Mean (SD) }\end{array}$ & $\begin{array}{c}\text { Care Homes } \\
(N=39) \\
\text { Mean (SD) }\end{array}$ & $\begin{array}{c}\text { Current Study } \\
\text { Cronbach's } \\
\text { Alpha }\end{array}$ & $\begin{array}{c}\text { CFA } \\
\text { GFI; NFI; CFI }\end{array}$ \\
\hline \multirow[t]{3}{*}{ Comfort } & Bothered by noise in own room & $4.20(0.90)$ & $4.03(1.01)$ & 0.79 & $1.00 ; 1.00 ; 1.00$ \\
\hline & Bothered by noise elsewhere in the village & $4.42(0.67)$ & $3.94(1.07)$ & & \\
\hline & Get a good night sleep & $4.18(0.96)$ & $4.11(0.99)$ & & \\
\hline Privacy & Staff knock \& wait before entering & $4.82(0.63)$ & $4.39(1.02)$ & -- & -- \\
\hline \multirow[t]{3}{*}{ Dignity } & Staff treats you politely & $4.85(0.39)$ & $4.53(0.65)$ & 0.84 & $1.00 ; 1.00 ; 1.00$ \\
\hline & Staff treats you with respect & $4.81(0.44)$ & $4.57(0.69)$ & & \\
\hline & Staff takes time to listen to you & $4.68(0.58)$ & $4.11(1.04)$ & & \\
\hline \multirow{3}{*}{$\begin{array}{l}\text { Meaningful } \\
\text { Activities }\end{array}$} & Give helps to others & $3.84(1.01)$ & $3.51(1.26)$ & 0.56 & $0.99 ; 1.00 ; 1.00$ \\
\hline & $\begin{array}{l}\text { Enjoys organised activities here at the } \\
\text { village/ care home }\end{array}$ & $3.46(1.00)$ & $4.08(0.97)$ & & \\
\hline & The days here seem too long to you & $3.96(0.98)$ & $3.46(1.04)$ & & \\
\hline \multirow[t]{5}{*}{ Relationships } & Easy to make friends at the village/care home & $3.88(0.93)$ & $3.64(1.10)$ & 0.65 & $0.99 ; 0.97 ; 1.00$ \\
\hline & Consider any resident to be close friend & $3.34(1.27)$ & $3.14(1.18)$ & & \\
\hline & Staff stop just to have friendly conversation & $3.57(0.91)$ & $3.60(1.17)$ & & \\
\hline & Consider 1 or more staff to be a friend & $3.24(1.25)$ & $3.49(0.87)$ & & \\
\hline & $\begin{array}{l}\text { Village /care homes makes it easy for family \& } \\
\text { friends to visit }\end{array}$ & $4.35(0.79)$ & $4.36(0.93)$ & & \\
\hline \multirow{4}{*}{$\begin{array}{l}\text { Positive } \\
\text { Mental Health }\end{array}$} & I am in good spirits most of the time & $4.04(0.66)$ & $3.94(0.79)$ & 0.78 & $0.98 ; 0.94 ; 0.96$ \\
\hline & I feel happy most of the time & $4.11(0.60)$ & $3.91(0.84)$ & & \\
\hline & I think it is wonderful to be alive now & $4.01(0.87)$ & $3.81(0.89)$ & & \\
\hline & I feel full of energy & $3.17(0.95)$ & $2.90(1.02)$ & & \\
\hline \multirow{3}{*}{$\begin{array}{l}\text { Loneliness \& } \\
\text { Isolation }\end{array}$} & I often feel bored & $3.98(0.94)$ & $3.62(1.13)$ & 0.71 & $1.00 ; 1.00 ; 1.00$ \\
\hline & I feel lonely & $3.89(1.07)$ & $3.44(1.19)$ & & \\
\hline & I often feel helpless & $3.98(1.02)$ & $3.38(1.30)$ & & \\
\hline \multirow{3}{*}{$\begin{array}{l}\text { Subjective } \\
\text { Wellbeing }\end{array}$} & Perceived quality of life & $4.15(0.67)$ & $3.90(0.91)$ & 0.76 & $1.00 ; 1.00 ; 1.00$ \\
\hline & Satisfied with your current living place & $4.30(0.81)$ & $3.90(0.91)$ & & \\
\hline & Satisfied with life as a whole & $4.16(0.76)$ & $4.00(0.73)$ & & \\
\hline
\end{tabular}

Note. *All scales are ranged from 1 to 5 ; higher the number means more positive in feelings and self-perceived perspectives.

\#Yeung et al., 2016; Yeung \& Rodgers, 2017. 
the assumptions of multicolinearity and singularity (i.e., that all variables entered into the equation were related to the dependent variable to at least a minimal degree $(r>0.3)$ but not too highly $(r<0.7)$ to other independent variables. Only variables that were significantly correlated with SWB were used for regression analysis. A power calculation showed our sample size was sufficient to demonstrate a true difference at a significance level of $5 \%$ and power of $80 \%$ (Tabachnick \& Fidell, 2013).

\section{Results}

The general background of the village residents who participated in the survey is that they identified themselves as mostly as NZ European/Pākehā (>80\%). Women constituted a greater proportion than did men $(72.9 \%$ compared to $27.1 \%)$. The age range was between 60.0 and 103.0, with over $50 \%$ reported aged $75+$. This aligns with existing research that most residents enter around 73 years of age and the average age within the village is 79 years, therefore reporting the $75+$ penetration ration (Jones Lang LaSalle, 2015). The length of resident stay reported by the participants was an average of five years.

The mean scores of Comfort, Privacy and Dignity that contributed to SWB among village residents were all above 4.00 , indicating fairly positive experience in these areas. Satisfaction mean scores on Meaningful Activities and Relationships were between 3.24 and 4.35 , indicating relatively acceptable level of satisfaction. These satisfaction scores are slightly higher than the RAC residents reported in both our study (Yeung et al., 2016; Yeung \& Rodgers, 2017) and Burack and colleagues' (2012) study. In general, residents of retirement villages and RAC facilities were reported to have similar mean scores on PMH items relating to psychological resources and strengths. Village residents in general did not report particularly high concern over feeling lonely or isolated. Although RAC residents did not score as high as village residents on not experiencing substantial levels of loneliness and isolation, their scores were still above average ( $>3.40$ out of 5.00 ).

Overall, all the variables demonstrated acceptable to high internal consistency (between 0.56 to 0.84 ). In addition, results of CFA indicated good construct validity from all domains, except Privacy due to having only one item.

The four variables, which were found to be significantly correlated with SWB, were entered into the regression equation. As can be seen in Table 2, PMH $(r=0.55), L \mathcal{E}(r=0.49)$, Dignity $(r=0.30)$ and Relationships $(r=0.29)$ correlated significantly with SWR with their effects ranging from small to large (Cohen, 1988). The regression model explains $47 \%$ of variance in $\mathrm{SWB}$, which is statistically significant $(F(4,145)=33.34, p<0.001)$. All four independent variables, namely $P M H$ $(\beta=0.43, \mathrm{p}=0.00), L \mathcal{L} I(\beta=0.27, \mathrm{p}=0.00)$, Dignity $(\beta=0.17, \mathrm{p}=0.01)$, and Relationship $(\beta=0.13, \mathrm{p}=0.04)$ were found to make a unique and significant contribution to SWB.

\section{Discussion}

As many older people prefer living independently in their own environment, the emergence of retirement villages represents a promising alternative living option for older people in Aotearoa New Zealand. Consistent with other studies (Edvardsson \& Innes, 2010; White et al., 2008), the current research provides an indicative result that the use of residential satisfaction could be a good indicator to measure the psychological wellbeing of older people in their own living situations. The retirement village model strives to enhance independence, security and privacy while offering diverse services and support to satisfy residents' needs and demands (Gardner et al., 2005). There are two important findings from this research. Firstly, the current study demonstrates that residents are generally satisfied with their retirement village living experiences and their overall wellbeing is positively influenced by their social and psychological milieu. This is also 
Table 2. Correlation Between Subjective Wellbeing and Other Domain Variables Among Village Residents

\begin{tabular}{|c|c|c|c|c|c|c|c|}
\hline Factors & $\begin{array}{c}1 \\
\text { (1-item }\end{array}$ & $\begin{array}{c}2 \\
\text { (3-item) }\end{array}$ & $\begin{array}{c}3 \\
\text { (1-item) }\end{array}$ & $\begin{array}{c}4 \\
\text { (3-item) }\end{array}$ & $\begin{array}{c}5 \\
\text { (3-item) }\end{array}$ & $\begin{array}{c}6 \\
\text { (5-item) }\end{array}$ & $\begin{array}{c}7 \\
\text { (4-item) }\end{array}$ \\
\hline 1. SWB & -- & & & & & & \\
\hline 2. $\mathrm{COM}$ & -0.06 & -- & & & & & \\
\hline 3. PVY & 0.07 & $0.16^{*}$ & -- & & & & \\
\hline 4. DIG & $0.30^{* *}$ & 0.09 & 0.14 & -- & & & \\
\hline 5. MA & 0.03 & 0.07 & 0.12 & 0.09 & -- & & \\
\hline 6. REL & $0.29^{\star *}$ & -0.03 & -0.04 & $0.28^{\star \star}$ & 0.05 & -- & \\
\hline 7. $\mathrm{PMH}$ & $0.55^{\star *}$ & 0.07 & 0.01 & 0.10 & 0.08 & $0.37^{* *}$ & -- \\
\hline 8. L\&I & 0.49 ** & -0.05 & 0.11 & 0.16 & -0.08 & 0.16 & $0.41^{* \star}$ \\
\hline
\end{tabular}

Note. $N=163$. SWB = subjective wellbeing; $\mathrm{COM}=$ comfort; $\mathrm{PVY}=$ privacy; $\mathrm{DIG}=$ dignity; $\mathrm{MA}=$ meaningful activities; REL = relationship; $\mathrm{PMH}=$ positive mental health; $\mathrm{L} \& \mathrm{I}=$ loneliness and isolation

${ }^{*} p<0.05$ (two-tailed); ${ }^{* *} p<0.01$ (two-tailed)

Strength of the relationship: small $(r=0.10$ to 0.29$)$; medium ( $r=030$ to 0.49$)$; and large $(r=0.50$ to 1.0$)$

(Cohen, 1988)

Table 3. Predictors of Subjective Wellbeing Among Village Residents

\begin{tabular}{|l|c|c|c|c|c|c|c|c|}
\hline Variables entered & $R$ & $R^{2}$ & Adj. $R^{2}$ & $F$ & $P$ & $B(\mathrm{SE})$ & $\begin{array}{c}95 \% \mathrm{Cl} \text { for } B \\
\text { (lower; upper) }\end{array}$ & $P$ \\
\hline Model & 0.69 & 0.48 & 0.47 & 33.34 & 0.00 & & & \\
\hline Dignity & & & & & & $0.17(0.25)$ & $0.18 ; 1.17$ & $0.01^{*}$ \\
\hline Relationship & & & & & & $0.13(0.14)$ & $0.18 ; 1.17$ & $0.04^{*}$ \\
\hline Positive Mental Health & & & & & & $0.43(0.19)$ & $0.82 ; 1.57$ & $0.00^{* *}$ \\
\hline Loneliness and isolation & & & & & & $0.27(0.14)$ & $0.29 ; 0.83$ & $0.00^{* *}$ \\
\hline
\end{tabular}

${ }^{* *} p<0.001 ;{ }^{*} p<0.05$

illustrated in the following comment made by one of the village residents:

We have a little unit here and this is our home, at first, that was home in the unit, but as you got out and got to know other people, home became the other parts of [the village]. Going down to happy hour and sitting there and seeing all these people, they're like your family.

Residents seem able to meet their emotional needs and aspirations through village living. These results are in line with those of previous studies which emphasise that retirement village environments should be designed to meet fundamental needs such as maintaining independence, supportiveness, security, promoting social capital and meaningful participation in order to combat loneliness and isolation, and create a sense of belonging and social integration (Crisp et al., 2013; Graham \& Tuffin, 2004).

Secondly, being able to compare life in a retirement village and a care home within the same complex gives valuable information. This information could be made available to consumers and this can help older adults and/or their family members to assess what matter most in relation to quality of living when considering relocation to a retirement village. Information for stakeholders may include provision for continuing healthcare needs emphasised with a resident-centred care practice, home maintenance support, and the convenient location of facilities to maintain social connection in order to 
make an informed decision on their housing options. Many retirees may consider the option of retirement communities when they are still fully able to live independently. However, negative perceptions related to relocating to a retirement village can have a negative impact on residents' self-concept and their relationships with others (Bohle et al., 2014) which could further impact on their decision to move into assisted living or care home facilities due to declining health. Results from this study further emphasise the importance of a home-like environment for both retirement village and care home residents within the mandate of residentcentred care practice. To enable retirement village residents to consider their potential future living in a care home, aged care providers need to move towards residentcentred and relation-based care focusing on supporting residents' aspirations to living in care, rather than existing in care (Yeung et al., 2016). One of the village residents supported the organisation's change of care philosophy to resident-centred to help her envisage care home options for future needs:

...trying to get away from the place being institutionalized and making it like home, and having the things that you like around you, and having the children and animals around, having nice gardens, and having a say in what happens, which is happening more and more here. We're not being told you do this you do that, we're being asked if this is what we'd like to do. Just making a place that was just a big place of units and houses into a proper home, your own home.

Another village resident also commented on the importance of resident-centred care:

I heard about the Eden Alternative philosophy. I think my understanding of it is the bottom line that people would actually listen to residents, what they would like, what they think they need, whether that's supplied or not is completely different, but at least feel like you are being taken noticed of, being listened to, which still doesn't always happen.

If retirement village residents access care services at relatively older ages, this would mean support received in villages can enable them to continue to age in their own place until there is a need to move to a care home adjacent to the retirement village. This could be a good option if one member of a couple requires more care. One could live in the village and the other close by.

Some gerontologists have argued that ageing in one place may be more appropriate than making multiple moves while ageing, although older people's needs and levels of independence change as they age, which will require accommodation in physical, social and infrastructure (Towart, 2013). While the current study has limited socio-demographic data and limited general health status information on these village residents, they reported good levels of subjective wellbeing. Although diverse services, including assisted living or RAC facilities, are available in the retirement villages, not all of these services are currently preferred nor frequently used by this cohort of residents due to their relatively healthy status. While some of them acknowledged different kinds of activities available, the general feeling was that many of the village residents continued (and preferred) to maintain their own personal and social networks within or outside of the village. They considered that their physical and functional independence makes them different from those who require the kind of living offered in the RAC or assisted living. This is echoed by one of the village residents:

Yeah, people have said to me that unless you're in the care facility, it's not going to affect us [having someone to come and help with care] very much, or not at all in fact. We do all hope that we won't go there one day. That doesn't mean any disrespect to it, it's just the way you feel you know.

As the proportion of New Zealanders aged 65 and over is expected to double in size 
from $13 \%$ to $26 \%$ of the population by 2050 (OECD, 2015), questions continue to be raised in relation to how retirement villages can meet older people's needs as they continue to age over time. Existing literature indicates that relocation that involves major lifestyle change could impact adversely on older people's health and wellbeing during later-life transition (Heisler et al., 2004; Rowles, 1978; Rubinstein \& Parmelee, 1992). As morbidity and disability are more prevalent in later life, due to agerelated impairments, it is vital for aged care organisations and staff to consider what will be required for residents with changing needs to move and adapt to other settings.

Overall, moving from retirement villages to RAC may not be a simple journey for older people. Cheek et al. (2006) have argued that some of the older people and their families in their study thought living in a co-located complex would give the older person a seamless on-demand transition from retirement village to RAC facility. However, the urgency to move from a retirement village to RAC could be an ad hoc one due to health crisis or loss of a care-providing spouse, resulting in little or limited time to consult with the provider and this can cause a great deal of frustration for older people and their families. Zimmerman and Dabelko (2007) have reported that, while social workers have been identified as crucial collaborators in transitional care, the process often involves mainly nursing staff. Much of the literature on RAC residents' wellbeing tend to be nursing care-focused while social workers have been peripheral to aged care service provision, even though the needs of older people, especially during the transition to RAC, may be addressed by core social work skills, such as family work, community work, resourcing and advocacy (Hugman, 2000; Wilson, Setterlund, \& Tilse, 2003). Some international literature has illustrated social workers have been employed across the continuum of long-term care for older people in settings such as hospitals, nursing homes, and primary care (Allen, Nelson, Netting, \& Cox, 2007; Petersen, Wilson,
Wright, Ward, \& Capra, 2016). Despite their essential roles, social workers continued to express difficulty working in a traditional medical model of care with objective measurable and function tasks, rather than care that is underpinned by a meaningful relationship based on respect and trust (Rockwell, 2012; Yeung \& Rodgers, 2017). In Aotearoa New Zealand, Thornton (2012) argues that District Health Boards (DHBs) do not consistently provide services such as social work to meet the transition and emotional needs of older people moving into RAC facilities. Social workers' competencies and skills can be useful to deal with these types of issues. Social work has long been viewed as having an excellent understanding of the importance of collaboration, autonomy and empowerment of patients and their families in residential care facilities (Koenig, Lee, MacMillan, Fields, \& Spano, 2014). McKenna and Staniforth (2017) have identified the importance of social work services through transition and in residential care facilities can have substantial impact in empowering the move and adjustment for older people.

While not all retirement village residents will relocate to RAC, for those who do, social workers' professional knowledge and skills can contribute to the process of transitional care by providing more education for older people regarding early identification of health issues, promoting positive views on living in RAC facilities and guiding families in decision making. Social workers can also assist family members by providing information and communication to help them to understand the healthcare system, the range of care options that are available and how to access them. The admission to RAC facilities may occur under crisis circumstances and this can create stress and anxiety among residents and family. Changes in levels of care may also be interpreted as crises. Bern-Klug et al. (2009) state that social workers should be part of the core group assessing how well the facility is doing with transitions of care and be available to support residents and family to deal with any difficulties with transitions. In addition, it 
is salient for social workers to recognise that quality of care relationship equates to quality of life for older people who are residents of long-term care facilities. Social workers can work collaboratively with staff and the aged care organisation to acknowledge the life experience of residents in the facility and make it more like home. Older people value being recognised when others become involved in their lives (Shapiro, Setterlund, Warburton, O'Connor, \& Cumming, 2009). In providing the least restrictive living environment in which to age, social workers can support RAC residents to identify and pursue their own needs and preferences using strength-based relational practice instead of relying on facility activities alone (Rockwell, 2012). This is essential to good quality care as this can be neglected in busy facilities when the emphasis is mainly on providing technical nursing and medical care.

\section{Limitations}

These data must be interpreted with caution because only two retirement villages were involved in the study which limits the generalizability of the findings. Existing research has reported that retirement villages tend to comprise older people who are European/Pākehā, financially secure with fewer health and disability concerns (Graham et al., 2014). Towart (2013) argues that village residents are not generally wealthy as many of them rely on a retirement pension and will be sensitive to costs as their needs increase with age. Since the collection of socio-demographics of the study cohort were limited, our analysis was limited by the homogeneity of the sample with no economic, and education data, prompting more research to be recommended to better understand how retirement villages may impact on the diverse range of older people in Aotearoa New Zealand. Furthermore, the measurement and data collection were already pre-determined by the residential aged care organisation; hence, not all standardised items from some measurements were used despite the current selected instruments showing good reliability and construct validity. Only four interviews were conducted with retirement village residents; hence, the limited scope of qualitative data can only be used as a complement to the quantitative results. Data collection also relied solely on self-report measures in a cross-sectional design which prevents any examination of the quality indicators over time to preclude causal inferences as older people tend to report more positively which may skew results. In addition, the amount of variance explained by the regression model (i.e., $47 \%$ ) suggests that there may be other variables that could contribute to the determinants of subjective wellbeing among older people living in retirement villages.

\section{Conclusions}

As the ageing population grows, an increasing number of people are relocating to retirement villages which offer independent living surrounded by facilities and support services. This study set out to investigate factors that contribute to wellbeing among older people living in retirement villages. The results of this investigation have shown that dignity, having meaningful relationships with others, maintaining positive mental health and not feeling lonely and isolated contributed to retirement village residents' subjective wellbeing. In an increasingly competitive market environment, consumers want to make informed decisions about relocation in later life. Results from our study on retirement village residents enable comparison with care home residents on what matters most to quality of life and care satisfaction. Such information could well result in an economic edge for aged care providers to develop further strategies to offer quality of care for extended ageing in place. Overall, this study suggests that retirement villages represent a promising new trend to provide alternative housing options to reduce social isolation, enhance wellbeing and increase older people's confidence to maintain independence. However, as older people proceed through their life course, they periodically will have to assess the appropriateness of their housing and living conditions. The decision 
to relocate can be difficult for older adults and it can be mitigated by factors such as health, financial capacity, and location of the facility. Therefore, more innovative models of care are needed to provide the benefits of retirement accommodation but still be flexible and affordable for those with limited financial capacity and increasing support needs.

\section{References}

Allen, P., Nelson, H., Netting, F., \& Cox, D. (2007). Navigating conflict: A model for nursing home social workers. Health \& Social Work, 32(3), 231-234.

Bern-Klug, M., Kramer, K.W.O., Chan, G., Kane, R., Dorfman, L.T., \& Saunders, J. B. (2009). Characteristics of nursing home social services directors: How common is a degree in social work? Journal of the American Medical Directors Association, 10(1), 36-44.

Black, K., \& Dobbs, D. (2014). Community-dwelling older adults' perceptions of dignity: Core meanings, challenges, supports and opportunities. Ageing \& Society, 34(8), 1292-1313.

Bohle, O., Rawlings-Way, O., Finn, J., Ang, J., \& Kennedy, D. (2014). Housing choice in retirement: Community versus separation. Housing Studies, 29(1), 108-127.

Brownie, S., \& Horstmanshof, L. (2012). Creating the conditions for self-fulfilment for aged care residents. Nursing Ethics, 19(6), 777-786.

Burack, O. R., Weiner, A.S., Reinhardt, J. P., \& Annunziato, R. A. (2012). What matters most to nursing home elders: Quality of life in the nursing home. Journal of the American Medical Directors Associations, 13(1), 48-53.

Chandler, R. C., \& Robinson, O. C. (2014). Wellbeing in retirement villages: Eudaimonic challenges and opportunities. Journal of Aging Studies, 31, 10-19.

Cheek, J., Ballantyne, A., Byers, L., \& Quan, J. (2006). Improving the retirement village to residential aged care transition. Australian Health Review, 30(3), 344-352.

Cohen, J. W. (1988). Statistical power analysis for the behavioural sciences $\left(2^{\text {nd }}\right.$ ed.). Hillsdale, $\mathrm{NJ}$ : Lawrence Erlbaum Associates.

Crisp, D., Windsor, T., Anstey, K. J., \& Butterworth, P. (2013). What are older adults seeking? Factors encouraging or discouraging retirement village living. Australasian Journal of Ageing, 32(3), 163-170.

Edvardsson, D., \& Innes, A. (2010). Measuring personcentered care: A critical comparative review of published tools. The Gerontologist, 50(6), 834-846.

Emlet, C. A., \& Moceri, J. T. (2012). The importance of social connectedness in building age-friendly communities. Journal of Aging Research, 1-9. http://dx.doi.org/10.1155/ 2012/173247

Ferris, C., \& Bramston, P. (1994). Quality of life in the elderly: A contribution to its understanding. Australian Journal on Ageing, 13(3), 120-123.

Fisher, B. J. (1987). Illness career descent in institutions for the elderly. Qualitative Sociology, 10, 132-145.
Gardner, I. L., Browning, C., \& Kendig, H. (2005). Accommodation options in later life: Retirement village or community living? Australasian Journal on Ageing, 24(4), 188-195.

Graham, C. L., Scharlach, A. E., \& Wolf, J. P. (2014). The impact of the "village" model on health, well-being, service access, and social engagement of older adults, Health Education \& Behavior, 41(1S), 91S-97S.

Graham, V., \& Tuffin, K. (2004). Retirement villages: Companionship, privacy and security. Australasian Journal on Ageing, 23(4), 84-188.

Grant, B. C. (2007). Retirement villages: More than enclaves for the aged. Activities, Adaptation \& Aging, 31(2), 37-55.

Heisler, E. G., Evans, W., \& Moen, P. (2004). Health and social outcomes of moving to a continuing care retirement community. Journal of Housing for the Elderly, 18, 5-24.

Howe, A. L., Jones, A. E., \& Tilse, C. (2013). What's in a name? Similarities and differences in international terms and meanings for older peoples' housing with services. Ageing \& Society, 33, 547-578.

Hu, L., \& Bentler, P. M. (1999). Cutoff criteria for fit indexes in covariance structure analysis: Conventional criteria versus new alternatives. Structural Equation Modeling, 6(1), 1-55.

Hu, X., Xia, B., Skitmore, M., Buys, L., \& Zuo, J. (2017). Retirement villages in Australia: A literature review. Pacific Rim Property Research Journal, 23(1), 101-122.

Hugman, R. (2000). Older people and their families: Rethinking the social work task? Australian Social Work, 53(1), 3-8.

Jenkins, K. R., Pienta, A. M., \& Horgas, A. L. (2002) Activity and health-related quality of life in continuing care retirement communities. Research on Aging, 24, 124-149.

Jones Lang LaSalle (2015). The 2015 New Zealand retirement village database (NZRVD). Retrieved from http://www.rvranz.org.nz/uploads/4/3/9/2/43925677/ village_database_2015.pdf

Joreskog, K. G., \& Sorbom, D. (1989). LISREL 7: A guide to the program and applications (2nd ed.). Chicago, IL: SPSS Inc.

Kane, R. A., Kling, K. C, Bershadsky, B., Kane, R. L., Giles, K., Degenholtz, H. B., Liu, J., \& Cutler, L. J. (2003). Quality of life measures for nursing home participants. Journal of Gerontology: Medical Sciences, 58(3), 240-248.

Kennedy, D. J., \& Coates, D. (2008). Retirement village resident satisfaction in Australia: A qualitative enquiry. Journal of Housing for the Elderly, 22, 311-334.

Klinedinst, J. N., \& Resnick, B. (2014). Volunteering and depressive symptoms among residents in a continuing care retirement community. Journal of Gerontological Social Work, 57(1), 52-71.

Koenig, T., Lee, H.J., MacMillan, K. R., Fields, N. L., \& Spano, R. (2014). Older adult and family member perspectives of the decision-making process involved in moving to assisted living. Qualitative Social Work, 13(3), 335-350.

La Grow, S., Yeung, P., Towers, A., Alpass, F., \& Stephens, C. (2011). Determinants of the overall quality of life of older persons who have difficulty seeing: The importance 
of the ability to get around. Journal of Visual Impairment \& Blindness, 105(10), 720-730.

Manicaros, M., \& Stimson, R. (1999). Living in a retirement village: Attitudes, choices and outcomes. Brisbane, QLD: Australian Housing and Urban Research Institute.

McKenna, D., \& Staniforth, B. (2017). Older people moving to residential care in Aotearoa New Zealand: Considerations for social work at practice and policy levels. Aotearoa New Zealand Social Work, 29(1), 28-40.

McLaughlin, T., \& Mills, A. (2008). Where will we live when we get older? Quality in Ageing and Older Adults, 9(3), 5-21.

Meek, G. (2011). The benefits of providing nursing services to retirement village residents. Kai Tiaki Nursing New Zealand, 17(9), 16-18.

Ministry of Health. (2002). Health of older people strategy. Wellington, New Zealand: Author.

Moen, P., Erickson, M.A., \& Dempster-McCain, D. (2000). Social role identities among older adults in a continuing care retirement community. Research on Aging, $22,559-579$

Montague, M. (1982). Ageing and autonomy: Who makes decisions for older people in supported accommodation? Melbourne, VIC: Brotherhood of St Laurence.

New Zealand Law Commission. (1999). Report 57 retirement villages. Wellington, NZ: Government Print.

OECD (2015). Health at a Glance 2015: OECD Indicators. Paris, France: OECD Publishing. Retrieve from http://apps.who.int/medicinedocs/documents/s22177en/ s22177en.pdf

Petersen, M., Wilson, J., Wright, O., Ward, E., \& Capra, S (2016). The space of family care-giving in Australian aged care facilities: Implications for social work. British Journal of Social Work, 46, 81-97.

Retirement Villages Association of New Zealand. (2005). About the retirement village association. Retrieved from http://www.retirementvillages.org.nz/Site/About_RVA/ Default.aspx

Rockwell, J. (2012). From person-centered to relational care: Expanding the focus in residential care facilities. Journal of Gerontology Social Work, 55(3), 233-248.

Rowles, G. D. (1978). Prisoners of space? Exploring the geographical experience of older people. Boulder, CO: Westview Press.

Rubinstein, R. L. \& Parmelee, P. A. (1992). Attachment to place and the representation of the life course by the elderly. In I. Altman \& S. M. Low (Eds.), Place attachment (pp. 139-164). New York, NY: Plenum.

Shapiro, M., Setterlund, D., Warburton, J., O'Connor, I., \& Cumming, S. (2009). The outcomes research project: An exploration of customary practice in Australian health settings. The British Journal of Social Work, 39(2), 318-333.

Sheikh, J. I., \& Yesavage, J. A. (1986). Geriatric depression scale (GDS): Recent evidence and development of a shorter version, Clinical Gerontologist, 5(1-2), 165-173.

Shippee, T. P. (2012). On the edge: Balancing health, participation, and autonomy to maintain active independent living in two retirement facilities. Journal of Aging Studies, 26, 1-15.
Statistics New Zealand. (2014). National population projections: 2014(base)-2068. Retrieved from http://www.stats.govt.nz/browse for_stats/ population/estimates_and_projections/ NationalPopulationProjections_HOTP2014.aspx

Stimson, R., McCrea, R., \& Star, L. (2002), "What retirees look for in a retirement village." In R. Stimson (Ed.), The retirement village industry in Australia: Evolution, prospects, challenges (pp. 73-88). Brisbane, QLD: University of Queensland Press.

Tabachnick, B. G., \& Fidell, L. S. (2013). Using multivariate statistics (6th ed.). Boston, MA: Pearson Education.

Thornton, G. (2012). Aged residential care service review. Wellington, NZ: Thornton New Zealand. Retrieved from https://nzaca.org.nz/assets/Documents/ARSCR-FullReport.pdf

Towart, L. C. (2013). Who lives in retirement villages: Are they wealthy enclaves, ghettos or connected communities? In K. Ruming, B. Randolph, \& N. Gurran (Eds.), State of Australian Cities Conference: Refereed Proceedings (pp. 1-11). Sydney, NSW: State of Australian Cities Research Network.

U'Ren, B. (2013). Retirement housing and medical facilities: Preference, proximity and price (Unpublished doctoral thesis). Bond University, Gold Coast, Queensland.

Webster, A. (2015). New Zealand retirement village database. Whitepaper May 2015. Retrieve from http://www.jll.nz/new-zealand/en-gb/Research/JLL_ NZRVD_2015_whitepaper_low.pdf

Webster, A. (2017). New Zealand Retirement Village Database (NZRVD) November 2016. Retrieve from http://www.jll.nz/new-zealand/en-gb/Research/jll-nzretirement-village-whitepaper-2017.pdf

White, D., Newton-Curtis, L., \& Lyons, K. S. (2008). Development and initial testing of a measure of persondirected care. Gerontologist, 48(1), 114-123.

Wilson, J., Setterlund, D., \& Tilse, C. (2003). "I know I signed something": Older people, families and social workers' understanding of the legal aspects of entry to residential care. Australian Social Work, 56(2), 155-165.

Yeung, P. \& Breheny, M. (2016). Using the capability approach to understand the determinants of subjective well-being among community-dwelling older people in New Zealand. Age \& Ageing, 45(2), 292-298.

Yeung, P., Rodgers, V., Dale, M., Spence, S., Ros, B., Howard, J., \& O'Donoghue, K. (2016). Psychometric testing of a person-centred care scale the Eden Warmth Survey in a long-term care home in New Zealand. Contemporary Nurse, 52(2-3), 176-190. doi:10.1080/ 10376178.2016.1198236

Yeung, P., \& Rodgers, V. (2017). Quality of long-term care for older people in residential settings: Perceptions of quality of life and care satisfaction from residents and their family members. Nursing Praxis in New Zealand. Journal of Professional Nursing, 33(1), 28-43.

Zimmerman, J., \& Dabelko, H. (2007). Collaborative models of patient care. Social Work in Health Care, 44(4), 33-47. 